\title{
On the split common fixed point problem for strict pseudocontractive and asymptotically nonexpansive mappings in Banach spaces
}

Jinfang Tang ${ }^{1}$, Shih-sen Chang ${ }^{2,3 *}$, Lin Wang ${ }^{3}$ and Xiongrui Wang ${ }^{1}$

"Correspondence:

changss2013@mail.cmu.edu.tw

${ }^{2}$ Center for General Education,

China Medical University, Taichung,

40402, Taiwan

${ }^{3}$ College of Statistics and

Mathematics, Yunnan University of

Finance and Economics, Kunming,

Yunnan 650221, China

Full list of author information is

available at the end of the article

\begin{abstract}
In this paper, we prove a weak convergence theorem and a strong convergence theorem for split common fixed point problem involving a quasi-strict pseudo contractive mapping and an asymptotical nonexpansive mapping in the setting of two Banach spaces. Our results are new and seem to be the first outside Hilbert spaces.

MSC: $47 \mathrm{H} 09 ; 49 J 25$

Keywords: split common fixed point problem; asymptotical nonexpansive mapping; strict pseudocontractive mapping; quasi-strict pseudocontractive mapping
\end{abstract}

\section{Introduction}

Let $H_{1}$ and $H_{2}$ be two real Hilbert spaces, $C$ and $Q$ be nonempty closed convex subsets of $H_{1}$ and $H_{2}$, respectively, and $A: H_{1} \rightarrow H_{2}$ be a bounded linear operator. The split feasibility problem (SFP) is formulated as to find a point $q \in H_{1}$ such that

$$
q \in C \text { and } A q \in Q \text {. }
$$

It is easy to see that $q \in C$ solves equation (1.1) if and only if it solves the following fixed point equation:

$$
q=P_{C}\left(I-\gamma A^{*}\left(I-P_{Q}\right) A\right) q, \quad x \in C,
$$

where $P_{C}$ (resp. $P_{Q}$ ) is the (orthogonal) projection from $H_{1}$ (resp. $H_{2}$ ) onto $C$ (resp. Q), $\gamma>0$, and $A^{*}$ is the adjoint of $A$.

Let $S: C \rightarrow C$ and $T: Q \rightarrow Q$ be two mappings. The so-called split common fixed point problem (SCFP) for mappings $S$ and $T$ is to find a point $q \in C$ such that

$$
q \in F(S) \text { and } A q \in F(T)
$$

(c) 2015 Tang et al. This article is distributed under the terms of the Creative Commons Attribution 4.0 International License (http://creativecommons.org/licenses/by/4.0/), which permits unrestricted use, distribution, and reproduction in any medium, provided you give appropriate credit to the original author(s) and the source, provide a link to the Creative Commons license, and indicate if changes were made. 
where $F(S)$ and $F(T)$ denote the sets of fixed points of $S$ and $T$, respectively. We use $\Gamma$ to denote the set of solutions of SCFP for mappings $S$ and $T$, that is,

$$
\Gamma=\{q \in F(S): A q \in F(T)\} .
$$

The SFP in finite-dimensional Hilbert spaces was first introduced by Censor and Elfving [1] for modeling inverse problems which arise from phase retrievals and in medical image reconstruction [2]. The split common fixed point problems in Hilbert spaces were introduced by Moudafi [3] in 2010. Since then, various algorithms have been invented to solve SFP and SCFP [4-16]. In 2014, Cui and Wang [17] investigated the split common fixed point problems of $\tau$-quasi-strict pseudocontractive mappings in the setting of two Hilbert spaces.

In 2015, Takahashi [18], Takahashi and Yao [19] first attempted to introduce and consider the split feasibility problem and split common null point problem in the setting of a Banach space. By using hybrid methods and Halpern-type methods and under suitable conditions, some strong and weak convergence theorems for such kinds of problems are obtained. The results presented in [18] and [19] seem to be the first outside Hilbert spaces.

Motivated and inspired by the research going on in the direction of split feasibility problems and split common fixed point problems, we have the purpose in this article to consider and study the split common fixed point problem for a $\tau$-quasi-strict pseudocontractive mapping and asymptotical nonexpansive mappings in the setting of two Banach spaces. We construct an iterative scheme to approximate a solution for such kind of split common fixed point problem in the setting of two Banach spaces. Our results are new and seem to be the first outside Hilbert spaces on this problem.

\section{Preliminaries}

Throughout this paper, we assume that $E$ is a real Banach space with the dual $E^{*}$ and $C$ is a nonempty closed convex subset of $E$. Let $T$ be a mapping. We denote by $F(T)$ the set of fixed points of $T$. We denote by ' $\rightarrow$ ' and ' $\rightarrow$ ' strong convergence and weak convergence, respectively.

In the sequel, we denote by $J: E \rightarrow 2^{E^{*}}$ the normalized duality mapping defined by

$$
J x=\left\{x^{*} \in E^{*}:\left\langle x, x^{*}\right\rangle=\|x\|^{2}=\left\|x^{*}\right\|^{2}\right\}, \quad \forall x \in E,
$$

where $\langle\cdot, \cdot\rangle$ is the generalized duality pairing between $E$ and $E^{*}$.

A Banach space $E$ is said to be strictly convex if $\frac{\|x+y\|}{2}<1$ for all $x, y \in U=\{z \in E:\|z\|=1\}$ with $x \neq y$. The modulus of convexity of $E$ is defined by

$$
\delta_{E}(\epsilon)=\inf \left\{1-\left\|\frac{1}{2}(x+y)\right\|:\|x\|,\|y\| \leq 1,\|x-y\| \geq \epsilon\right\}
$$

for all $\epsilon \in[0,2]$. $E$ is said to be uniformly convex if $\delta_{E}(0)=0$ and $\delta_{E}(\epsilon)>0$ for all $0<\epsilon \leq 2$.

Let $\rho_{E}:[0, \infty) \rightarrow[0, \infty)$ be the modulus of smoothness of $E$ defined by

$$
\rho_{E}(t)=\sup \left\{\frac{1}{2}(\|x+y\|+\|x-y\|)-1: x \in U,\|y\| \leq t\right\} .
$$


A Banach space $E$ is said to be uniformly smooth if $\frac{\rho_{E}(t)}{t} \rightarrow 0$ as $t \rightarrow 0$. Let $q>1$ be a fixed number. Then a Banach space $E$ is said to be $q$-uniformly smooth if there exists a constant $c>0$ such that $\rho_{E}(t) \leq c t^{q}$ for all $t>0$. It is well known that every $q$-uniformly smooth Banach space is uniformly smooth.

Lemma 2.1 Let E be a uniformly convex Banach space. Then, for any given number $r>0$, there exists a continuous strictly increasing function $g:[0, \infty) \rightarrow[0, \infty), g(0)=0$ such that

$$
\|t x+(1-t) y\|^{2} \leq t\|x\|^{2}+(1-t)\|y\|^{2}-t(1-t) g(\|x-y\|)
$$

for all $x, y \in E$ with $\|x\| \leq r$ and $\|y\| \leq r, t \in[0,1]$.

Lemma 2.2 If $E$ is a 2-uniformly smooth Banach space with the best smoothness constants $k>0$, then the following inequality holds:

$$
\|x+y\|^{2} \leq\|x\|^{2}+2\langle y, J x\rangle+2\|k y\|^{2}, \quad \forall x, y \in E .
$$

Definition 2.3 Let $T: C \rightarrow C$ be an operator. Then

(i) $T$ is said to be $\left\{k_{n}\right\}$-asymptotically nonexpansive if there exists a sequence $\left\{k_{n}\right\} \subset[1, \infty)$ with $k_{n} \rightarrow 1$ such that

$$
\left\|T^{n} x-T^{n} y\right\| \leq k_{n}\|x-y\|, \quad \forall n \geq 1, x, y \in C ;
$$

(ii) $T$ is said to be $\tau$-strict pseudocontractive if there exists a constant $\tau \in[0,1)$ such that

$$
\|T x-T y\|^{2} \leq\|x-y\|^{2}+\tau\|(I-T) x-(I-T) y\|^{2}, \quad \forall x, y \in C ;
$$

(iii) $T$ is said to be $\tau$-quasi-strict pseudocontractive if $F(T) \neq \emptyset$ and there exists a constant $\tau \in[0,1)$ such that

$$
\|T x-p\|^{2} \leq\|x-p\|^{2}+\tau\|(I-T) x\|^{2}, \quad \forall p \in F(T), x \in C .
$$

Example of $\left\{k_{n}\right\}$-asymptotically nonexpansive mapping Let $C$ be a unit ball in a real Hilbert $l^{2}$, and let $T: C \rightarrow C$ be a mapping defined by

$$
T:\left(x_{1}, x_{2}, \ldots\right) \rightarrow\left(0, x_{1}^{2}, a_{2} x_{2}, a_{3} x_{3}, \ldots\right)
$$

where $\left\{a_{i}\right\}$ is a sequence in $(0,1)$ such that $\prod_{i=2}^{\infty} \alpha_{i}=\frac{1}{2}$.

It is proved in Goebel and Kirk [20] that

(i) $\|T x-T y\| \leq 2\|x-y\|, \forall x, y \in C$;

(ii) $\left\|T^{n} x-T^{n} y\right\| \leq 2 \prod_{i=2}^{n} a_{j}\|x-y\|, \forall n \geq 2$ and $x, y \in C$.

Denote by $k_{1}^{\frac{1}{2}}=2, k_{n}^{\frac{1}{2}}=2 \prod_{i=2}^{n} a_{i}, n \geq 2$, then

$$
\lim _{n \rightarrow \infty} k_{n}=\lim _{n \rightarrow \infty}\left(2 \prod_{i=2}^{n} a_{i}\right)^{2}=1 .
$$


Therefore $\forall x, y \in C, n \geq 1$, we have

$$
\left\|T^{n} x-T^{n} y\right\|^{2} \leq k_{n}\|x-y\|^{2} .
$$

This implies that $T$ is a $\left\{k_{n}\right\}$-asymptotically nonexpansive mapping.

Example of $\tau$-strict pseudocontractive mapping Now, we give an example of a $\tau$-strict pseudocontractive mapping.

Let $X=l^{2}$ with the norm $\|\cdot\|$ defined by

$$
\|x\|=\sqrt{\sum_{i=1}^{\infty} x_{i}^{2}}, \quad \forall x=\left(x_{1}, x_{2}, \ldots, x_{n}, \ldots\right) \in X,
$$

and $C=\left\{x=\left(x_{1}, x_{2}, \ldots, x_{n}, \ldots\right) \in l^{2}: x_{i} \in R^{1}, i=1,2, \ldots\right\}$ be an orthogonal subspace of $X$ (i.e., we assume that the set $C$ satisfies the condition that for any $x, y \in C$, we have $\langle x, y\rangle=0)$. It is obvious that $C$ is a nonempty closed convex subset of $X$. For each $x=\left(x_{1}, x_{2}, \ldots, x_{n}, \ldots\right) \in C$, we define a mapping $T: C \rightarrow C$ by

$$
T x= \begin{cases}\left(x_{1}, x_{2}, \ldots, x_{n}, \ldots\right) & \text { if } \prod_{i=1}^{\infty} x_{i}<0 \\ \left(-x_{1},-x_{2}, \ldots,-x_{n}, \ldots\right) & \text { if } \prod_{i=1}^{\infty} x_{i} \geq 0 .\end{cases}
$$

Next we prove that $T$ is a $\tau$-strict pseudocontractive mapping and $F(T) \neq \emptyset$, therefore it is a $\tau$-quasi-strict pseudocontractive mapping.

In fact, for any $x, y \in C$, we have the following.

Case 1. If $\prod_{i=1}^{\infty} x_{i}<0$ and $\prod_{i=1}^{\infty} y_{i}<0$, then we have $T x=x, T y=y$, and so inequality (2.1) holds.

Case 2. If $\prod_{i=1}^{\infty} x_{i}<0$ and $\prod_{i=1}^{\infty} y_{i} \geq 0$, then we have that $T x=x, T y=-y$. This implies that

$$
\left\{\begin{array}{l}
\|T x-T y\|^{2}=\|x-(-1) y\|^{2}=\|x\|^{2}+\|y\|^{2} \\
\|x-y\|^{2}=\left(\|x\|^{2}+\|y\|^{2}\right) \\
\|x-T x-(y-T y)\|^{2}=[1-(-1)]^{2}\|y\|^{2}
\end{array}\right.
$$

Therefore inequality (2.1) holds.

Case 3. If $\prod_{i=1}^{\infty} x_{i} \geq 0$ and $\prod_{i=1}^{\infty} y_{i} \geq 0$, then we have $T x=(-1) x, T y=(-1) y$. Hence we have

$$
\left\{\begin{array}{l}
\|T x-T y\|^{2}=\|(-1) x-(-1) y\|^{2}=\|x-y\|^{2}=\|x\|^{2}+\|y\|^{2}, \\
\|x-y\|^{2}=\left(\|x\|^{2}+\|y\|^{2}\right), \\
\|x-T x-(y-T y)\|^{2}=[1-(-1)]^{2}\|x-y\|^{2}=[1-(-1)]^{2}\left(\|x\|^{2}+\|y\|^{2}\right) .
\end{array}\right.
$$

Thus inequality (2.1) still holds. Therefore the mapping defined by (2.4) is a $\tau$-strict pseudocontractive mapping. Since $\theta=(0,0,0, \ldots, 0,0, \ldots) \in C$ and $T(\theta)=\theta$, the set $F(T)$ of fixed points of $T$ in $C$ is nonempty. Therefore $T$ is also a $\tau$-quasi-strict pseudocontractive mapping.

\section{Definition 2.4}

(1) Let $T: C \rightarrow C$ be a mapping with $F(T) \neq \emptyset$. Then $T$ is said to be demiclosed at zero if for any $\left\{x_{n}\right\} \subset C$ with $x_{n} \rightarrow x$ and $\left\|x_{n}-T x_{n}\right\| \rightarrow 0, x=T x$. 
(2) Let $E$ be a Banach space. $E$ is said to have the Opial property if for any sequence $\left\{x_{n}\right\}$ in $E$ with $x_{n} \rightarrow x^{*}$, for any $y \in E$ with $y \neq x^{*}$, we have

$$
\liminf _{n \rightarrow \infty}\left\|x_{n}-x^{*}\right\|<\liminf _{n \rightarrow \infty}\left\|x_{n}-y\right\| .
$$

Definition 2.5 A mapping $T: C \rightarrow C$ is said to be semi-compact if for any bounded sequence $\left\{x_{n}\right\} \subset C$ such that $\left\|x_{n}-T x_{n}\right\| \rightarrow 0(n \rightarrow \infty)$, there exists a subsequence $\left\{x_{n_{j}}\right\}$ of $\left\{x_{n}\right\}$ such that $\left\{x_{n_{j}}\right\}$ converges strongly to $x^{*} \in C$.

Lemma 2.6 Let $\left\{a_{n}\right\},\left\{b_{n}\right\}$ and $\left\{\delta_{n}\right\}$ be sequences of nonnegative real numbers satisfying

$$
a_{n+1} \leq\left(1+\delta_{n}\right) a_{n}+b_{n}, \quad \forall n \geq 1
$$

If $\sum_{n=1}^{\infty} \delta_{n}<\infty$ and $\sum_{n=1}^{\infty} b_{n}<\infty$, then the limit $\lim _{n \rightarrow \infty} a_{n}$ exists.

\section{Main results}

Throughout this section, we assume that:

(1) $E_{1}$ is a real uniformly convex and 2-uniformly smooth Banach space having the Opial property and the best smoothness constant $k$ satisfying $0<k<\frac{1}{\sqrt{2}}$.

(2) $E_{2}$ is a real Banach space.

(3) $A: E_{1} \rightarrow E_{2}$ is a bounded linear operator and $A^{*}$ is the adjoint of $A$.

(4) $S: E_{1} \rightarrow E_{1}$ is an $\left\{l_{n}\right\}$-asymptotical nonexpansive mapping with $\left\{l_{n}\right\} \subset(1, \infty)$ and $l_{n} \rightarrow 1 . T: E_{2} \rightarrow E_{2}$ is a $\tau$-quasi-strict pseudocontractive mapping with $F(S) \neq \emptyset$ and $F(T) \neq \emptyset$, and $T$ is demiclosed at zero.

Remark It follows from condition (1) that $E_{1}$ is a real smooth, strictly convex and reflexive Banach space. Therefore, as is well known, the normalized duality mapping $J_{1}: E_{1} \rightarrow 2^{E_{1}^{*}}$ is single-valued, one-to-one and onto. And $J_{1}^{-1}: E_{1}^{*} \rightarrow 2^{E_{1}}$ is also single-valued, one-to-one and onto.

We are now in a position to introduce and study the following split common fixed point problem (SCFP) for an asymptotical nonexpansive mapping $S$ and a $\tau$-quasipseudocontractive mapping $T$ in the setting of two Banach spaces, i.e., to find

$$
p \in F(S) \text { such that } A p \in F(T)
$$

where $F(S)$ and $F(T)$ are the sets of fixed points of $S$ and $T$, respectively. In the sequel we use $\Gamma$ to denote the set of solutions of (SCFP) (3.1) for mappings $S$ and $T$, that is,

$$
\Gamma=\{p \in F(S): A p \in F(T)\} .
$$

Theorem 3.1 Let $E_{1}, E_{2}, A, S, T$ and $\left\{l_{n}\right\}$ be the same as above. For each $x_{1} \in E_{1}$, let $\left\{x_{n}\right\}$ be the sequence generated by

$$
\left\{\begin{array}{l}
z_{n}=x_{n}+\gamma J_{1}^{-1} A^{*} J_{2}(T-I) A x_{n}, \\
x_{n+1}=\left(1-\alpha_{n}\right) z_{n}+\alpha_{n} S^{n} z_{n}, \quad \forall n \geq 1,
\end{array}\right.
$$

where $\left\{\alpha_{n}\right\}$ is a sequence in $(0,1)$ with $\liminf _{n \rightarrow \infty} \alpha_{n}\left(1-\alpha_{n}\right)>0, \gamma$ is a positive constant satisfying $0<\gamma<\min \left\{\frac{1-2 k^{2}}{\|A\|^{2}}, \frac{1-\tau}{\|A\|^{2}}\right\},\left\{l_{n}\right\}$ is a sequence in $[1,+\infty)$ with $L=\sup _{n \geq 1}\left\{l_{n}\right\}$ and $\sum_{n=1}^{\infty}\left(l_{n}-1\right)<\infty$. 
(I) If $\Gamma=\{p \in F(S): A p \in F(T)\} \neq \emptyset$ (the set of solutions of (SCFP) (3.1)), then the sequence $\left\{x_{n}\right\}$ converges weakly to a point $x^{*} \in \Gamma$.

(II) In addition, if $\Gamma=\{p \in F(S): A p \in F(T)\} \neq \emptyset$ and $S$ is semi-compact, then $\left\{x_{n}\right\}$ converges strongly to a point $x^{*} \in \Gamma$.

Proof Now we prove conclusion (I).

We divide the proof into four steps.

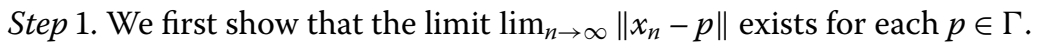

For any given $p \in \Gamma$, we have $p \in F(S)$ and $A p \in F(T)$. It follows from (3.3) and Lemma 2.2 that

$$
\begin{aligned}
&\left\|z_{n}-p\right\|^{2} \\
&=\left\|\left(x_{n}-p\right)+\gamma J_{1}^{-1} A^{*} J_{2}(T-I) A x_{n}\right\|^{2} \\
& \leq\left\|\gamma J_{1}^{-1} A^{*} J_{2}(T-I) A x_{n}\right\|^{2}+2 \gamma\left\langle x_{n}-p, A^{*} J_{2}(T-I) A x_{n}\right\rangle+2 k^{2}\left\|x_{n}-p\right\|^{2} \\
& \leq \gamma^{2}\|A\|^{2}\left\|(T-I) A x_{n}\right\|^{2}+2 \gamma\left\langle A x_{n}-A p, J_{2}(T-I) A x_{n}\right\rangle+2 k^{2}\left\|x_{n}-p\right\|^{2} \\
&= \gamma^{2}\|A\|^{2}\left\|(T-I) A x_{n}\right\|^{2}+2 k^{2}\left\|x_{n}-p\right\|^{2} \\
&+2 \gamma\left\langle A x_{n}-T A x_{n}+T A x_{n}-A p, J_{2}(T-I) A x_{n}\right\rangle \\
&= \gamma^{2}\|A\|^{2}\left\|(T-I) A x_{n}\right\|^{2}+2 k^{2}\left\|x_{n}-p\right\|^{2} \\
&-2 \gamma\left\|(T-I) A x_{n}\right\|^{2}+2 \gamma\left\langle T A x_{n}-A p, J_{2}(T-I) A x_{n}\right\rangle \\
& \leq\left(\gamma^{2}\|A\|^{2}-2 \gamma\right)\left\|(T-I) A x_{n}\right\|^{2}+2 k^{2}\left\|x_{n}-p\right\|^{2} \\
&+\gamma\left(\left\|T A x_{n}-A p\right\|^{2}+\left\|(T-I) A x_{n}\right\|^{2}\right) \\
& \leq 2 k^{2}\left\|x_{n}-p\right\|^{2}-\gamma\left(1-\gamma\|A\|^{2}\right)\left\|(T-I) A x_{n}\right\|^{2} \\
&+\gamma\left\|A x_{n}-A p\right\|^{2}+\gamma \tau\left\|(T-I) A x_{n}\right\|^{2} \quad(b y(2.2)) \\
& \leq\left(2 k^{2}+\gamma\|A\|^{2}\right)\left\|x_{n}-p\right\|^{2}-\gamma\left(1-\tau-\gamma\|A\|^{2}\right)\left\|(T-I) A x_{n}\right\|^{2} \\
& \leq\left\|x_{n}-p\right\|^{2}-\gamma\left(1-\tau-\gamma\|A\|^{2}\right)\left\|(T-I) A x_{n}\right\|^{2} .
\end{aligned}
$$

It follows from (3.3), (3.4) and Lemma 2.1 that

$$
\begin{aligned}
&\left\|x_{n+1}-p\right\|^{2} \\
&=\left\|\left(1-\alpha_{n}\right)\left(z_{n}-p\right)+\alpha_{n}\left(S^{n} z_{n}-p\right)\right\|^{2} \\
& \leq\left(1-\alpha_{n}\right)\left\|z_{n}-p\right\|^{2}+\alpha_{n}\left\|S^{n} z_{n}-p\right\|^{2}-\alpha_{n}\left(1-\alpha_{n}\right) g\left(\left\|z_{n}-S^{n} z_{n}\right\|\right) \\
& \leq\left(1-\alpha_{n}\right)\left\|z_{n}-p\right\|^{2}+\alpha_{n} l_{n}\left\|z_{n}-p\right\|^{2}-\alpha_{n}\left(1-\alpha_{n}\right) g\left(\left\|z_{n}-S^{n} z_{n}\right\|\right) \\
&= {\left[1+\alpha_{n}\left(l_{n}-1\right)\right]\left\|z_{n}-p\right\|^{2}-\alpha_{n}\left(1-\alpha_{n}\right) g\left(\left\|z_{n}-S^{n} z_{n}\right\|\right) } \\
& \leq {\left[1+\alpha_{n}\left(l_{n}-1\right)\right]\left\|x_{n}-p\right\|^{2}-\gamma\left(1-\tau-\gamma\|A\|^{2}\right)\left\|(T-I) A x_{n}\right\|^{2} } \\
&-\alpha_{n}\left(1-\alpha_{n}\right) g\left(\left\|z_{n}-S^{n} z_{n}\right\|\right) \\
& \leq {\left[1+\alpha_{n}\left(l_{n}-1\right)\right]\left\|x_{n}-p\right\|^{2} . }
\end{aligned}
$$


From the condition $\sum_{n=1}^{\infty}\left(l_{n}-1\right)<\infty$ and Lemma 2.6 we know that $\lim _{n \rightarrow \infty}\left\|x_{n}-p\right\|$ exists. This implies that the sequence $\left\{x_{n}\right\}$ is bounded.

Step 2. We prove that $\lim _{n \rightarrow \infty}\left\|x_{n+1}-x_{n}\right\|=0$ and $\lim _{n \rightarrow \infty}\left\|z_{n+1}-z_{n}\right\|=0$.

From (3.5) we have

$$
\begin{aligned}
& \gamma\left(1-\tau-\gamma\|A\|^{2}\right)\left\|(T-I) A x_{n}\right\|^{2}+\alpha_{n}\left(1-\alpha_{n}\right) g\left(\left\|z_{n}-S^{n} z_{n}\right\|\right) \\
& \quad \leq\left[1+\alpha_{n}\left(l_{n}-1\right)\right]\left\|x_{n}-p\right\|^{2}-\left\|x_{n+1}-p\right\|^{2} .
\end{aligned}
$$

Letting $n \rightarrow \infty$ in the above inequality, we obtain

$$
\lim _{n \rightarrow \infty}\left\|(T-I) A x_{n}\right\|=0
$$

and

$$
\lim _{n \rightarrow \infty} g\left(\left\|z_{n}-S^{n} z_{n}\right\|\right)=0 .
$$

By virtue of Lemma 2.1 and the property of $g$, we know that the sequences $\left\{z_{n}\right\}$ and $\left\{S^{n} z_{n}\right\}$ are bounded and

$$
\lim _{n \rightarrow \infty}\left\|z_{n}-S^{n} z_{n}\right\|=0
$$

It follows from (3.3) that

$$
\begin{aligned}
\left\|x_{n+1}-x_{n}\right\| & =\left\|\left(1-\alpha_{n}\right) z_{n}+\alpha_{n} S^{n} z_{n}-x_{n}\right\| \\
& =\left\|\left(z_{n}-x_{n}\right)+\alpha_{n}\left(S^{n} z_{n}-z_{n}\right)\right\| \\
& \leq\left\|\gamma J_{1}^{-1} A^{*} J_{2}(T-I) A x_{n}\right\|+\alpha_{n}\left\|S^{n} z_{n}-z_{n}\right\| \\
& \leq \gamma\|A\|\left\|(T-I) A x_{n}\right\|+\alpha_{n}\left\|S^{n} z_{n}-z_{n}\right\| .
\end{aligned}
$$

From (3.7) and (3.8) we have that

$$
\lim _{n \rightarrow \infty}\left\|x_{n+1}-x_{n}\right\|=0
$$

Similarly,

$$
\begin{aligned}
\left\|z_{n+1}-z_{n}\right\| & =\left\|x_{n+1}+\gamma J_{1}^{-1} A^{*} J_{2}(T-I) A x_{n+1}-x_{n}-\gamma J_{1}^{-1} A^{*} J_{2}(T-I) A x_{n}\right\| \\
& \leq\left\|x_{n+1}-x_{n}\right\|+\left\|\gamma J_{1}^{-1} A^{*} J_{2}(T-I) A x_{n+1}\right\|+\left\|\gamma J_{1}^{-1} A^{*} J_{2}(T-I) A x_{n}\right\| \\
& \leq\left\|x_{n+1}-x_{n}\right\|+\gamma\|A\|\left\|(T-I) A x_{n+1}\right\|+\gamma\|A\|\left\|(T-I) A x_{n}\right\| .
\end{aligned}
$$

In view of (3.7), (3.10) and (3.11), we get

$$
\lim _{n \rightarrow \infty}\left\|z_{n+1}-z_{n}\right\|=0 .
$$

In addition, since

$$
\begin{aligned}
\left\|x_{n}-z_{n}\right\| & =\left\|J_{1}\left(x_{n}-z_{n}\right)\right\|=\left\|\gamma A^{*} J_{2}(T-I) A x_{n}\right\| \\
& \leq \gamma\|A\|\left\|(T-I) A x_{n}\right\|,
\end{aligned}
$$


from (3.7) we obtain

$$
\lim _{n \rightarrow \infty}\left\|x_{n}-z_{n}\right\|=0
$$

Step 3. We prove that $\lim _{n \rightarrow \infty}\left\|z_{n}-S z_{n}\right\|=0$.

By the assumption that $S$ is an asymptotical nonexpansive mapping and $L=\sup _{n \geq 1}\left\{l_{n}\right\}$, it follows from (3.8) and (3.12) that

$$
\begin{aligned}
& \left\|z_{n}-S z_{n}\right\| \\
& \quad \leq\left\|z_{n}-S^{n} z_{n}\right\|+\left\|S^{n} z_{n}-S z_{n}\right\| \\
& \quad \leq\left\|z_{n}-S^{n} z_{n}\right\|+L\left\|S^{n-1} z_{n}-z_{n}\right\| \\
& \quad \leq\left\|z_{n}-S^{n} z_{n}\right\|+L\left(\left\|S^{n-1} z_{n}-S^{n-1} z_{n-1}\right\|+\left\|S^{n-1} z_{n-1}-z_{n-1}\right\|+\left\|z_{n-1}-z_{n}\right\|\right) \\
& \quad \leq\left\|z_{n}-S^{n} z_{n}\right\|+L(L+1)\left\|z_{n}-z_{n-1}\right\|+L\left\|S^{n-1} z_{n-1}-z_{n-1}\right\| \\
& \quad \rightarrow 0 \quad(n \rightarrow \infty)
\end{aligned}
$$

i.e.,

$$
\lim _{n \rightarrow \infty}\left\|z_{n}-S z_{n}\right\|=0
$$

Step 4 . We prove that $\left\{x_{n}\right\}$ converges weakly to $x^{*} \in \Gamma$.

Since $E_{1}$ is uniformly convex, it is reflexive. By the boundedness of $\left\{x_{n}\right\}$, there exists a subsequence $\left\{x_{n_{i}}\right\}$ of $\left\{x_{n}\right\}$ such that $x_{n_{i}} \rightarrow x^{*}$. By virtue of (3.14), this implies that the subsequence $\left\{z_{n_{i}}\right\}$ of $\left\{z_{n}\right\}$ converges weakly to $x^{*}$, too. From (3.15) we obtain

$$
\left\|z_{n_{i}}-S z_{n_{i}}\right\| \rightarrow 0 \quad\left(n_{i} \rightarrow \infty\right)
$$

$S$ is an asymptotical nonexpansive mapping, it is demiclosed at zero. Hence $x^{*} \in F(S)$.

On the other hand, since $A$ is a bounded linear operator, we know that $\left\{A x_{n_{i}}\right\}$ converges weakly to $A x^{*}$. From (3.7) we have

$$
\left\|A x_{n_{i}}-T A x_{n_{i}}\right\| \rightarrow 0 \quad\left(n_{i} \rightarrow \infty\right)
$$

Since $T$ is demiclosed at zero, we have $A x^{*} \in F(T)$. This together with $x^{*} \in F(S)$ shows that $x^{*} \in \Gamma$.

Now we prove that $\left\{x_{n}\right\}$ converges weakly to $x^{*} \in \Gamma$.

In fact, if there exists another subsequence $\left\{x_{n_{j}}\right\}$ of $\left\{x_{n}\right\}$ such that $\left\{x_{n_{j}}\right\}$ converges weakly to $y^{*} \in \Gamma$, by virtue of Step 1 and the assumption that $E_{1}$ has the Opial property, we have

$$
\begin{aligned}
\liminf _{n_{i} \rightarrow \infty}\left\|x_{n_{i}}-x^{*}\right\| & <\liminf _{n_{i} \rightarrow \infty}\left\|x_{n_{i}}-y^{*}\right\|=\lim _{n \rightarrow \infty}\left\|x_{n}-y^{*}\right\| \\
& =\liminf _{n_{j} \rightarrow \infty}\left\|x_{n_{j}}-y^{*}\right\|<\liminf _{n_{j} \rightarrow \infty}\left\|x_{n_{j}}-x^{*}\right\| \\
& =\lim _{n \rightarrow \infty}\left\|x_{n}-x^{*}\right\|=\liminf _{n_{i} \rightarrow \infty}\left\|x_{n_{i}}-x^{*}\right\| .
\end{aligned}
$$

This is a contradiction. Therefore $\left\{x_{n}\right\}$ converges weakly to $x^{*} \in \Gamma$. The proof of conclusion (I) is completed. 
Next, we prove conclusion (II).

Since $\lim _{n \rightarrow \infty}\left\|z_{n}-S z_{n}\right\|=0$ and $S$ is semi-compact, there exists a subsequence $\left\{z_{n_{k}}\right\}$ of $\left\{z_{n}\right\}$ such that $\left\{z_{n_{k}}\right\}$ converges strongly to $\mu^{*} \in E_{1}$. By using (3.14), we know that the subsequence $\left\{x_{n_{k}}\right\}$ of $\left\{x_{n}\right\}$ converges strongly to $\mu^{*}$, too. Due to $\left\{x_{n}\right\}$ converging weakly to $x^{*}$, we have $\mu^{*}=x^{*}$. Since $\lim _{n \rightarrow \infty}\left\|x_{n}-x^{*}\right\|$ exists and $\lim _{n_{k} \rightarrow \infty}\left\|x_{n_{k}}-x^{*}\right\|=0$, we know that $\left\{x_{n}\right\}$ converges strongly to $x^{*} \in \Gamma$. This completes the proof of conclusion (II).

\section{Application to hierarchical variational inequality problem in Banach spaces}

In this section we shall utilize the results presented in Section 3 to study the hierarchical variational inequality problem in Banach spaces.

Let $E$ be a strictly convex and real reflexive Banach space and $K$ be a nonempty closed and convex subset of $E$. Then, for any $x \in E$, there exists a unique element $z \in K$ such that $\|x-z\| \leq\|x-y\|, \forall y \in K$. Putting $z=P_{K} x$, we call $P_{K}$ the metric projection of $E$ onto $K$.

Lemma 4.1 [21] Let E be a smooth, strictly convex and reflexive Banach space, and $K$ be a nonempty, closed and convex subset of $E$. Let $x \in E$ and $z \in K$. Then the following conditions are equivalent:

(i) $z=P_{K} x$;

(ii) $\langle z-y, J(x-z)\rangle \geq 0, \forall y \in K$,

where $J$ is the normalized duality mapping on $E$.

Definition 4.2 Let $E$ be a smooth, strictly convex and reflexive Banach space, and $K$ be a nonempty, closed and convex subset of $E$. Let $S: K \rightarrow K$ be a nonlinear mapping with $F(S)$ being a nonempty closed and convex subset of $K$ and $V: K \rightarrow K$ be a nonlinear mapping. The so-called hierarchical variational inequality problem for a mapping $S$ with respect to a mapping $V$ in Banach spaces is to find $x^{*} \in F(S)$ such that

$$
\left\langle x^{*}-x, J\left(V x^{*}-x^{*}\right)\right| \geq 0, \quad \forall x \in F(S) .
$$

By Lemma 4.1, the hierarchical variational inequality problem in Banach space (4.1) is equivalent to the following fixed point equation:

$$
x^{*}=P_{F(S)} V\left(x^{*}\right)
$$

Letting $C=F(S)$ and $Q=F\left(P_{F(S)} V\right)$ (the fixed point set of $P_{F(S)} V$ ) and $A=I$ (the identity mapping on $E$ ), then the hierarchical variational inequality problem (4.1) for a mapping $S$ with respect to a mapping $V$ in Banach space is equivalent to the following split common fixed point problem in Banach space:

$$
\text { to find } x^{*} \in C \text { such that } x^{*} \in Q \text {. }
$$

Therefore the set of solutions $\Gamma_{1}$ of hierarchical variational inequality problem (4.1) is just the set of solutions of split common fixed point problem (4.3).

Hence from Theorem 3.1 we have the following.

Theorem 4.3 Let E be a real uniformly convex and 2-uniformly smooth Banach space having the Opial property and the best smoothness constant $k$ satisfying $0<k<\frac{1}{\sqrt{2}}$. Let 
$S: E \rightarrow E$ be an $\left\{l_{n}\right\}$-asymptotical nonexpansive mapping with $F(S) \neq \emptyset$. Let $V: E \rightarrow E$ be a mapping such that the mapping $T:=P_{F(S)} V$ is a $\tau$-quasi-strict pseudocontractive mapping with $F(T) \neq \emptyset$ and $T$ is demiclosed at zero. For each $x_{1} \in E$, let $\left\{x_{n}\right\}$ be the sequence generated by

$$
\left\{\begin{array}{l}
z_{n}=x_{n}+\gamma(T-I) x_{n}, \\
x_{n+1}=\left(1-\alpha_{n}\right) z_{n}+\alpha_{n} S^{n} z_{n}, \quad \forall n \geq 1,
\end{array}\right.
$$

where $\left\{\alpha_{n}\right\}$ is a sequence in $(0,1)$ with $\liminf _{n \rightarrow \infty} \alpha_{n}\left(1-\alpha_{n}\right)>0, \gamma$ is a positive constant satisfying $0<\gamma<\min \left\{\left(1-2 k^{2}\right),(1-\tau)\right\},\left\{l_{n}\right\}$ is a sequence in $[1,+\infty)$ with $L=\sup _{n \geq 1}\left\{l_{n}\right\}$ and $\sum_{n=1}^{\infty}\left(l_{n}-1\right)<\infty$.

(I) If $\Gamma_{1}$ (the set of solutions of hierarchical variational inequality problem (4.1)) is nonempty, then the sequence $\left\{x_{n}\right\}$ converges weakly to a point $x^{*} \in \Gamma_{1}$.

(II) In addition, if $\Gamma_{1}$ is nonempty and $S$ is semi-compact, then $\left\{x_{n}\right\}$ converges strongly to a point $x^{*} \in \Gamma_{1}$.

Proof Taking $E_{1}=E_{2}=E, A=I, T=P_{F}(S) \circ V$ in Theorem 3.1, and noting that in this case $J_{1}=J_{2}=J$ (where $J$ is the normalized duality mapping on $E$ ), therefore the conclusion of Theorem 4.3 can be obtained from Theorem 3.1 immediately.

\section{A numerical example}

Throughout this section we assume that $E_{1}=E_{2}$ is a real Hilbert space $l^{2}, B$ is the unit ball in $l^{2}$, and $D=\left\{x=\left(x_{1}, x_{2}, \ldots, x_{n}, \ldots\right) \in l^{2}: x_{i} \in R^{1}, i=1,2, \ldots\right\}$ is an orthogonal subspace of $l^{2}$ (i.e., $\forall x, y \in C$, we have $\langle x, y\rangle=0$ ). Define $C:=B \cap D$. It is easy to know that $C$ is a nonempty closed and convex subset of $l^{2}$. Let $S: C \rightarrow C$ be a mapping defined by

$$
S:\left(x_{1}, x_{2}, \ldots\right) \rightarrow\left(0, x_{1}^{2}, a_{2} x_{2}, a_{3} x_{3}, \ldots\right), \quad\left(x_{1}, x_{2}, \ldots\right) \in C
$$

where $\left\{a_{i}\right\}$ is a sequence in $(0,1)$ such that $\prod_{i=2}^{\infty} \alpha_{i}=\frac{1}{2}$. Let $T: C \rightarrow C$ be a mapping defined by

$$
T x= \begin{cases}\left(x_{1}, x_{2}, \ldots, x_{n}, \ldots\right) & \text { if } \prod_{i=1}^{\infty} x_{i}<0 \\ \left(-x_{1},-x_{2}, \ldots,-x_{n}, \ldots\right) & \text { if } \prod_{i=1}^{\infty} x_{i} \geq 0\end{cases}
$$

for each $x=\left(x_{1}, x_{2}, \ldots, x_{n}, \ldots\right) \in C$. In (2.3) and (2.4), we have proved that $S: C \rightarrow C$ is $\left\{l_{n}\right\}$-asymptotically nonexpansive with $l_{1}=2, l_{n}=2 \prod_{i=2}^{n} a_{i}, n \geq 2$ and $F(S)=\{0\}$, while $T: C \rightarrow C$ is a $\tau$-quasi-strict pseudocontractive mapping with $F(T)=\{0\}$. Hence from Theorem 3.1 we can obtain the following.

Theorem 5.1 Let $E_{1}=E_{2}=l^{2}, C=B \cap D$ be the same as above. Let $S: C \rightarrow C$ be the $\left\{l_{n}\right\}$-asymptotically nonexpansive mapping and $T: C \rightarrow C$ be the $\tau$-quasi-strict pseudocontractive mapping defined by (5.1) and (5.2), respectively. Let $A: C \rightarrow C$ be a bounded linear operator and $A^{*}$ be the adjoint of $A$. For each $x_{1} \in C$, let $\left\{x_{n}\right\}$ be the sequence generated by

$$
\left\{\begin{array}{l}
z_{n}=P_{C}\left(x_{n}+\gamma A^{*}(T-I) A x_{n}\right), \\
x_{n+1}=\left(1-\alpha_{n}\right) z_{n}+\alpha_{n} S^{n} z_{n}, \quad \forall n \geq 1,
\end{array}\right.
$$


where $P_{C}$ is the projection from $l^{2}$ onto $C,\left\{\alpha_{n}\right\}$ is a sequence in $(0,1)$ with $\liminf _{n \rightarrow \infty} \alpha_{n}(1-$ $\left.\alpha_{n}\right)>0$, and $\gamma$ is a positive constant satisfying $0<\gamma<\frac{1-\tau}{\|A\|^{2}}$. If $\sum_{n=1}^{\infty}\left(l_{n}-1\right)<\infty$, then the conclusions of Theorem 3.1 hold.

\section{Competing interests}

The authors declare that they have no competing interests.

\section{Authors' contributions}

All authors contributed equally to the writing of this paper. All authors read and approved the final manuscript.

\section{Author details}

${ }^{1}$ College of Mathematics, Yibin University, Yibin, Sichuan 644007, China. ${ }^{2}$ Center for General Education, China Medical University, Taichung, 40402, Taiwan. ${ }^{3}$ College of Statistics and Mathematics, Yunnan University of Finance and Economics, Kunming, Yunnan 650221, China.

\section{Acknowledgements}

This work was supported by the Scientific Research Fund of Sichuan Provincial Department of Science and Technology (No. 2015JY0165) and the Scientific Research Project of Yibin University (No. 2013YY06) and the National Natural Science Foundation of China (No. 11361070).

Received: 14 June 2015 Accepted: 18 September 2015 Published online: 29 September 2015

\section{References}

1. Censor, Y, Elfving, T: A multiprojection algorithm using Bregman projections in a product space. Numer. Algorithms 8 , 221-239 (1994)

2. Byrne, C: Iterative oblique projection onto convex sets and the split feasibility problem. Inverse Probl. 18, 441-453 (2002)

3. Moudafi, A: The split common fixed point problem for demi-contractive mappings. Inverse Probl. 26, 055007 (2010)

4. Zhao, J, Yang, Q: Several solution methods for the split feasibility problem. Inverse Probl. 21(5), 1791-1799 (2005)

5. Qu, B, Xiu, N: A note on the CQ algorithm for the split feasibility problem. Inverse Probl. 21(5), 1655-1665 (2005)

6. Censor, Y, Elfving, T, Kopf, N, Bortfeld, T: The multiple-sets split feasibility problem and its applications. Inverse Probl. 21, 2071-2084 (2005)

7. $\mathrm{Xu}, \mathrm{H}-\mathrm{K}$ : Iterative methods for the split feasibility problem in infinite-dimensional Hilbert spaces. Inverse Probl. 26(10), 105018 (2010)

8. Yang, L, Chang, SS, Cho, YJ, Kim, JK: Multiple-set split feasibility problems for total asymptotically strict pseudocontractions mappings. Fixed Point Theory Appl. 2011, 77 (2011)

9. Moudafi, A: A note on the split common fixed point problem for quasi-nonexpansive operators. Nonlinear Anal. 74, 4083-4087 (2011)

10. Chang, SS, Cho, YJ, Kim, JK, Zhang, W, Yang, L: Multiple-set split feasibility problems for asymptotically strict pseudocontractions. Abstr. Appl. Anal. 2012, Article ID 491760 (2012). doi:10.1155/2012/491760

11. Chang, SS, Wang, L, Tang, YK, Yang, L: The split common fixed point problem for total asymptotically strictly pseudocontractive mappings. J. Appl. Math. 2012, Article ID 385638 (2012). doi:10.1155/2012/385638

12. Quan, J, Chang, SS, Zhang, X: Multiple-set split feasibility problems for $k$-strictly pseudononspreading mapping in Hilbert spaces. Abstr. Appl. Anal. 2013, Article ID 342545 (2013). doi:10.1155/2013/342545

13. Kim, JK, Chang, SS, Cho, YJ, Sim, JY: Weak and strong convergence theorems of solution to split feasibility problem for nonspreading type mapping in Hilbert spaces. Fixed Point Theory Appl. 2014, 11 (2014). doi:10.1186/1687-1812-2014-11

14. Tang, JF, Chang, SS: Strong convergence theorem of two-step iterative algorithm for split feasibility problems. J. Inequal. Appl. 2014, 280 (2014)

15. Tang, JF, Chang, SS, Yuan, F: A strong convergence theorem for equilibrium problems and split feasibility problems in Hilbert space. Fixed Point Theory Appl. 2014, 36 (2014)

16. Zhang, XF, Wang, L, Ma, ZL, Duan, W: The strong convergence theorems for split common fixed point problems of asymptotically nonexpansive mappings in Hilbert spaces. J. Inequal. Appl. 2015, 1 (2015)

17. Cui, HH, Wang, FH: Iterative methods for the split common fixed point problem in Hilbert spaces. Fixed Point Theory Appl. 2014, 78 (2014). doi:10.1186/1687-1812-2014-78

18. Takahashi, W: Iterative methods for split feasibility problems and split common null point problems in Banach spaces. In: The 9th International Conference on Nonlinear Analysis and Convex Analysis, Chiang Rai, Thailand, 21-25 January (2015)

19. Takahashi, W, Yao, J-C: Strong convergence theorems by hybrid methods for the split common null point problem in Banach spaces. Fixed Point Theory Appl. 2015, 87 (2015)

20. Goebel, K, Kirk, WA: A fixed point theorem for asymptotically nonexpansive mappings. Proc. Am. Math. Soc. 35 171-174 (1972)

21. Takahashi, W: Nonlinear Functional Analysis. Yokohama Publishers, Yokohama (2000) 